\title{
A REPORT ON CLINICAL PREVALENCE OF DISEASES AND DISORDERS IN CATTLE AND GOATS AT THE UPAZILLA VETERINARY HOSPITAL, MOHAMMADPUR, MAGURA
}

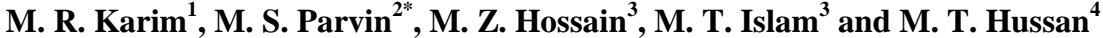 \\ ${ }^{1}$ Faculty of Animal Science and Veterinary Medicine, Patuakhali Science and Technology University, Babugonj, \\ Barishal-8210, Bangladesh, ${ }^{2}$ Department of Medicine, ${ }^{3}$ Department of Physiology, Faculty of Veterinary \\ Science, Bangladesh Agricultural University, Mymensingh-2202, Bangladesh, ${ }^{4}$ Department of Anatomy and \\ Histology, Faculty of Animal Science and Veterinary Medicine, Patuakhali Science and Technology University, \\ Babugonj, Barishal-8210, Bangladesh
}

\begin{abstract}
An investigation was undertaken to determine the general clinical prevalence of diseases and disorders in cattle and goats at the Upazilla Veterinary Hospital, Mohammadpur, Magura during the period from January to December 2010. A total of 536 clinical cases (327 cattle and 209 goats) were recorded and analyzed. Diagnosis of each of the clinical cases was made on general examination, physical examination, clinical examination, microscopic examination and using common laboratory techniques. The clinical cases were divided into three groups on the basis of treatment required viz. (1) Medicinal, (2) Gynaeco-obstetrical and (3) Surgical cases. Among the three types of ruminant cases, medicinal cases constituted highest percentage (cattle $86.5 \%$ and goats $90.4 \%$ ) in comparison to gynaeco-obstetrical (cattle $6.1 \%$ and goats $0.9 \%$ ) and surgical (cattle $7.3 \%$ and goats $8.6 \%$ ) cases. Among the medicinal cases, gastrointestinal nematodiasis (cattle 37.8\% and goats $19.6 \%$ ), diarrhoea (cattle $13.4 \%$ and goats $19.6 \%$ ), fascioliasis (cattle $12.4 \%$ and goats $1.6 \%$ ), paramphistomiasis (cattle $8.8 \%$ and goats $2.6 \%$ ), fever (cattle $7.8 \%$ and goats $12.7 \%$ ) were recorded major disease problems in cattle and goats. Among the gynaeco-obstetrical cases, retained placenta (cattle 30\% and goats 50\%) and repeat breeding (cattle $70 \%$ and goats $50 \%$ ) were recorded as major gynaeco-obstetrical problems in cattle and goats. Abscess (cattle 45.8\% and goats 5.6\%), myiasis (cattle $20.8 \%$ and goats $20.8 \%$ ), navel ill (cattle 12.5), urolithiasis (cattle $20.8 \%$ and goats $44.4 \%$ ) and overgrown hoof (goats $33.3 \%$ ) and gid disease (goats $5.6 \%$ ) were recognized as the main disorders which required surgical interventions. It may conclude that a number of diseases have been occurring in the Mohammadpur upazila and this report may help to develop control strategies against major diseases reported in this study.
\end{abstract}

Key words: Clinical prevalence, diseases and disorders, cattle, goat

\section{INTRODUCTION}

Livestock is an important component of the mixed farming system practiced in Bangladesh for centuries. Ruminant, especially cattle and goats constitute the major portion of the livestock. Most of these animals are reared under smallholder traditional management system in rural areas. The management practices of animals and geo-climatic condition of Bangladesh are favorable for the occurrence of various diseases. Veterinary hospital is an ideal and reliable source of information about animal diseases and their solution. People from the neighboring areas bring their sick animals to the Veterinary hospital every day. Analysis of the case record gives a comprehensive idea about the disease problems at local areas. Although some reports on clinical case records from Bangladesh Agricultural University Veterinary Clinic (Rahman et al., 1972; Hossain et al., 1986; Das and Hashim, 1996; Samad, 2001; Samad et al., 2002), Haluaghat Upazila Veterinary Hospital, Mymensingh (Sarker et al., 1999) and Dairy Cooperatives in Pabna district (Pharo, 1987), Ulipur Upazila Veterinary Hospital, Kurigram (Kabir et al., 2010), Chandanaish Upazila of Chittagong district, Bangladesh (Pallab et al., 2012) and Patuakhali Science and Technology University Veterinary Clinic (Rahman et al., 2012) are available but similar report on ruminants are very limited in Mohammadpur upazila of Magura district of Bangladesh. In the last few decades, as the major infectious diseases of cattle in Bangladesh are brought under control by vaccination and farmer's awareness, emphasis has increasingly shifted to economically important diseases to the dairy producers.

*Corresponding e-mail address: soniaparvin18@gmail.com 


\section{R. Karim and others}

However, more information is required to describe the pattern of occurrence of clinical diseases for the provision of appropriate veterinary care and effective disease control programme and animal production. The objective was to determine the clinical prevalence of diseases and disorders in cattle and goats at the Upazila Veterinary Hospital, Mohammadpur, Magura.

\section{MATERIALS AND METHODS}

This clinical study was undertaken at the Upazila Veterinary Hospital, Mohammadpur, Magura to determine the general clinical prevalence of clinical diseases and disorders in cattle and goats during the one year study period from January to December, 2010.

\section{General examination}

Physical condition, behavior, posture, gait, superficial skin wound, prolapse of the uterus and vagina, salivation, nasal discharge, distension of the abdomen, locomotive disturbance etc were observed by visual examination of the patient.

\section{Physical examination}

Examination of different parts and system of the body of each of the sick animals were examined by using procedure of palpation, percussion, auscultation, needle puncture and walking of the animals.

\section{Clinical examination}

The temperature, pulse, and respiratory rate from each of these sick animals were recorded. Clinical examinations of all 536 clinically sick ruminants (cattle $=327$, goat $=209$ ) of different ages were conducted on the basis of diseases history, owner complaint, symptoms, to diagnose the following diseases and disorders. History of each case (present and past) was carefully taken which gave a guideline for examination of the animals. According the merit of the individual case, general clinical examination were conducted on the basis of disease history and owners complaint, symptoms and techniques such as microscopic examination, common laboratory techniques used by Rosenberger (1979) and Samad et al. (1988). These recorded clinical cases were primarily categorized into three major groups on the basis of treatment required. These groups were: (1) Medicinal cases, (2) Gynaeco-obstetrical cases and (3) Surgical cases. These three groups that were considered sufficiently distinct so as to make clinical diagnosis accurate. However, the eye diseases which also include corneal opacity were included under medicinal cases because surgical intervention has never been practiced in Bangladesh (Osmani et al., 2000). Data were organized in the Microsoft ${ }^{\circledR}$ Excel spreadsheet and percentages of disease conditions prevalent in different diseases were calculated.

\section{RESULTS AND DISCUSSION}

Of the 327 recorded clinical cases of sick cattle, $86.5 \%$ was medicinal, $6.1 \%$ gynaeco-obstetrical and $7.3 \%$ surgical cases (Table 1). Of the 209 clinically sick goats, $90.4 \%$ had medicinal, $0.9 \%$ gynaeco-obstetrical and $8.6 \%$ surgical problems (Table 1). This observation supports the earlier report of Rahman et al. (2012) who recorded $84.1 \%$ medicinal, $4.7 \%$ gynaeco-obstetrical and $11.2 \%$ surgical cases in cattle; $81.0 \%$ medicinal, $1.1 \%$ gynaeco-obstetrical and $17.9 \%$ surgical cases in goats in Patuakhali Science and Technology University Veterinary Clinic, Babugonj, Barisal. Samad (2001) who recorded 90.76\% medicinal, 5.46\% gynaecoobstetrical and $3.78 \%$ surgical cases in cattle; $76.91 \%$ medicinal, $3.67 \%$ gynaeco-obstetrical and $19.42 \%$ surgical cases in goat during 1999 to 2001 from the Bangladesh Agricultural University (BAU) Veterinary Clinic, Mymensingh.

\section{Medicinal cases \\ Fever}

Analysis of the clinical cases of ruminants revealed that $7.8 \%$ cattle and $12.7 \%$ goats were affected with fever of unknown etiology. The percentages of occurrence of fever in this study supports the earlier reports of $5.1 \%$ to $12.1 \%$ cases of fever in cattle (Pharo, 1987; Hoque and Samad, 1996; Samad, 2001; Samad et al., 2002; Rahman et al., 2012) and $10.37 \%$ and $4.4 \%$ fever cases in goats (Hoque and Samad, 1997; Rahman et al., 2012). 
Prevalence of Diseases and Disorders in Cattle and Goats

\begin{abstract}
Anorexia
Anorexia was reported in $1.4 \%$ cattle and $7.4 \%$ in goats (Table 1). Prasad et al. (1980) recorded anorexia syndrome as one of the commonest problem amongst the non specific clinical entities in routine ruminant practice.

Bloat

Bloat is mainly a dietary in origin and occurs most frequently in ruminants in Bangladesh (Sutradhar et al., 2000). This study recorded $2.5 \%$ cases of bloat in cattle and $2.6 \%$ in goats (Table 1 ). The occurrence of bloat in cattle supports the earlier finding of Rahman et al. (2012) who reported $2.2 \%$ bloat in cattle and $2.5 \%$ in goats. Samad (2001) reported $1.83 \%$ prevalence of bloat in cattle and 3.98\% in goats. Sutradhar et al. (2000) reported $1.73 \%$ cases of bloat in cattle from some Upazila Veterinary Hospitals. These observations could be compared well with the findings of Hossain et al. (1994) and Rahman et al. (1999) who reported $4.0 \%$ and $0.37 \%$ prevalence of bloat in buffaloes and cattle, respectively.
\end{abstract}

\title{
Diarrhoea
}

Diarrhoea was found to be the major digestive disorders in ruminants. Diarrhoea cases were $13.4 \%$ in cattle and $19.6 \%$ in goats (Table 1). These observations could be compared well with the $6.94 \%$ of non-specific diarrhoea in dairy cows, $8.99 \%$ in cow-calves and $12.23 \%$ in goats (Hoque and Samad, 1996, 1997) and 7.6\% in cattle and $12.1 \%$ in goats (Rahman et al., 2012). Samad (2001) reported $25.97 \%$ and $9.91 \%$ of diarrhoeal diseases in cattle and goats, respectively. Rahman et al. (1999) reported $4.78 \%$ of diarrhoeal diseases in cattle.

\section{Dysentery}

Dysentery is characterized by inflammation of the intestine with evacuation of blood and mucus contained faeces, accompanied by tenesmus and colic. This disorder was recorded in $1.1 \%$ cattle and $6.3 \%$ goats (table 1 ). Samad (2001) reported $1.76 \%$ and $1.87 \%$ dysentery in cattle and goats.

\section{Pneumonia}

Pneumonia recorded in cattle and goats were $0.7 \%$ and $9.6 \%$, respectively (Table 1). Rahman et al. (2012) recorded $5.1 \%$ and $16.8 \%$ cases of pneumonia in cattle and goats. Cases of pneumonia in cattle were comparatively lower than the earlier reports of Samad (2001) and Samad et al. (2002) who reported 0.84\% and $1.24 \%$ pneumonia in cattle, respectively.

\section{Corneal opacity}

Corneal opacity in cattle and goats were recorded $0.4 \%$ and $2.6 \%$ under this group (Table 1). Rahman et al. (2012) reported $1.9 \%$ and $9.9 \%$ cases of corneal opacity in cattle and goats, respectively.

\footnotetext{
Mange

Mange was recorded in $4.6 \%$ cattle and $5.3 \%$ goats (Table 1). Cases of mange in cattle and goats were comparatively higher than the reports of Samad (2001) who recorded $0.33 \%$ in cattle and $2.11 \%$ in goats. Rahman et al. (1972) reported 2.08\% general prevalence of mange in cattle. However, Demodectic mange in cattle (Samad et al., 1979; Nooruddin and Rahman, 1985), psoroptic mange in goat (Rahman et al., 1978) has been reported from Bangladesh.
}

\section{Parasitic diseases}

The prevalence of different parasitic diseases were $12.4 \%$ and $1.6 \%$ Fascioliasis, $8.8 \%$ and $2.6 \%$ Paramphistomiasis, $37.8 \%$ and $19.6 \%$ Gastro-intestinal nematodiasis, $1.4 \%$ Ectoparasites, $1.4 \%$ and $1.1 \%$ Humpsore in cattle and goats, respectively (Table 1). Howlader et al. (1990) reported $21 \%$ sub clinical prevalence of Fascioliasis in cattle. However, this result differ from the earlier reports of Amin and Samad (1987) who reported $10.98 \%$ diarrhoea of cattle due to one or more groups of Nematode infestation. The clinical 


\section{R. Karim and others}

prevalence of Paramphistomiasis recorded in cattle has been reported from Bangladesh but detail studies on this disease have not yet been made from the country.

\section{Foot-and-mouth disease (FMD)}

This study recorded $2.5 \%$ cases of FMD in cattle (Table 1). This finding support the finding of Samad (2001) and Rahman et al. (2012) reported $1.79 \%$ and $1.3 \%$ cases of FMD in cattle and only one (0.08\%) case in goat. Comparatively higher prevalence rates of FMD in cattle have been reported by Rahman et al. (1972), Hoque and Samad (1996), Sarker et al. (1999) and Rahman et al. (1999) who reported 5.71\%, 10.05\%, 8.58\% and 5.78\%, respectively.

\section{Black quarter}

Black quarter (BQ) was diagnosed on the presence of pronounced swelling of the affected muscles of upper limb with gaseous crepitation. BQ was recorded in $4(1.4 \%)$ cattle (table 1). These observations support the earlier findings of Rahman et al. (1972), Rahman et al. (1999) and Samad (2001) who reported 0.31\%, 0.46\% and $0.23 \%$ incidence of BQ in cattle. However, Haque et al. (1988) reported 0.04\% and Hoque and Samad(1996) reported $2.17 \%$ incidence of BQ in cattle from different geographical location in Bangladesh.

\section{Papillomatosis}

This study recorded $0.7 \%$ cases of papillomatosis in cattle (Table 1). This findings support the reports of Nooruddin and Dey (1990), Samad (2001) and Rahman et al. (2012) reported and 0.7\%, 0.58\% and 0.19\% prevalence of warts in cattle from Bangladesh, respectively. However, Nooruddin et al. (1986) reported 3.04\% prevalence of warts under rural cattle.

\section{PPR}

This study recorded $5.3 \%$ cases of PPR in goats (Table 1). This finding support the finding of Rahman et al. (2012) who reported 5.2\% PPR cases in goats.

\section{Tetanus}

This study recorded $0.5 \%$ cases of tetanus in goats (Table 1). This finding support the finding of Samad (2001) and Rahman et al. (2012) reported $1.1 \%$ and $5.2 \%$ PPR cases in goats.

\section{Mastitis}

Mastitis $1.1 \%$ and $1.6 \%$ was diagnosed in cows and does (Table 1). The findings support the report of Sarker et al. (1999), Samad (2001) and Rahman et al. (2012) who reported clinical mastitis in 0.89\%, $0.71 \%$ and $0.9 \%$ cows, respectively. Nooruddin et al. (1986) and Rahman et al. (1999) also reported $0.37 \%$ and $0.65 \%$ clinical mastitis in cows.

\section{Gynaeco-obstetrical cases \\ Retained placenta}

This disorder was recorded only in $30 \%$ cows and $50 \%$ does (Table 1). This findings is contradicts with the reports of Rahman et al. (1999) and Samad (2001) who reported $0.37 \%$ and $0.50 \%$ cases of retained placenta in cows, respectively. Hossain et al. (1986) and Rahman et al. (2012) reported $9.1 \%$ and $8.1 \%$ cases of retained placenta in cows.

\section{Repeat breeding}

Repeat breeders are those female ruminants that fail to conceive after three or more regularly spaced services in the absence of detectable abnormalities of the internal genitalia (Samad, 2000). This disorder was recorded in $70.0 \%$ cattle and $50.0 \%$ goats (table 1). These findings support the observation of Rahman et al. (1975) and Hossain et al. (1986) who reported $22.0 \%$ and $63.0 \%$ incidence of repeat breeding syndrome among the reproductive disorders in cattle, respectively. However, Rahman et al. (1999) and Samad (2001) reported 0.64\% cattle and $1.26 \%$ and $0.24 \%$ prevalence of repeat breeder cattle and goats. 
Table 1. Clinical prevalence of diseases and disorders in cattle and goats recorded at Upazilla Veterinary Hospital, Mohammadpur, Magura

\begin{tabular}{|c|c|c|c|c|c|}
\hline \multirow[t]{2}{*}{$\mathrm{S} / \mathrm{N}$} & \multirow[t]{2}{*}{ Diseases } & \multicolumn{2}{|c|}{ Cattle $(n=327)$} & \multicolumn{2}{|c|}{ Goats $(n=209)$} \\
\hline & & $\begin{array}{l}\text { No. of } \\
\text { affected } \\
\text { cattle }\end{array}$ & Percentage (\%) & $\begin{array}{l}\text { No. of } \\
\text { affected } \\
\text { goats }\end{array}$ & $\begin{array}{c}\text { Percentage } \\
(\%)\end{array}$ \\
\hline 1. & Fever & 22 & 7.8 & 24 & 12.7 \\
\hline 2. & Anorexia & 4 & 1.4 & 14 & 7.4 \\
\hline 3. & Bloat & 7 & 2.5 & 5 & 2.6 \\
\hline 4. & Digestive disorder (Diarrhoea) & 38 & 13.4 & 37 & 19.6 \\
\hline 5. & Dysentery (Coccidiosis) & 3 & 1.1 & 12 & 6.3 \\
\hline 6. & Respiratory disorder (Pneumonia) & 2 & 0.7 & 18 & 9.5 \\
\hline 7. & Corneal opacity & 1 & 0.4 & 5 & 2.6 \\
\hline 8. & Mange & 13 & 4.6 & 10 & 5.3 \\
\hline 9. & Fascioliasis & 35 & 12.4 & 3 & 1.6 \\
\hline 10. & Paramphistomiasis & 25 & 8.8 & 5 & 2.6 \\
\hline 11. & Gastrointestinal nematodiasis & 107 & 37.8 & 37 & 19.6 \\
\hline 12. & Ectoparasitism & 4 & 1.4 & 0 & 0 \\
\hline 13. & Humpsore & 4 & 1.4 & 2 & 1.1 \\
\hline 14. & Foot and Mouth Disease & 7 & 2.5 & 0 & 0 \\
\hline 15. & Black quarter & 4 & 1.4 & 0 & 0 \\
\hline 16. & Papillomatosis & 2 & 0.7 & 0 & 0 \\
\hline 17. & PPR & 0 & 0 & 10 & 5.3 \\
\hline 18. & Tetanus & 0 & 0 & 1 & 0.5 \\
\hline 19. & Mastitis & 6 & 2.1 & 5 & 2.6 \\
\hline \multicolumn{2}{|c|}{ Sub-total (Medicinal cases) } & 283 & 86.5 & 189 & 90.4 \\
\hline 1. & Retained placenta & 6 & 30 & 1 & 50 \\
\hline 2. & Repeat breeders & 14 & 70 & 1 & 50 \\
\hline \multicolumn{2}{|c|}{ Sub-total (Gynaeco-obstetrical cases) } & 20 & 6.1 & 2 & 0.9 \\
\hline 1. & Abscess & 11 & 45.8 & 1 & 5.6 \\
\hline 2. & Myiasis & 5 & 20.8 & 2 & 11.1 \\
\hline 3. & Navel ill & 3 & 12.5 & 0 & 0 \\
\hline 4. & Gid disease & 0 & 0 & 1 & 5.6 \\
\hline 5. & Urolithiasis & 5 & 20.8 & 8 & 44.4 \\
\hline 6. & Overgrown Hoof & 0 & 0 & 6 & 33.3 \\
\hline \multicolumn{2}{|c|}{ Sub-total (Surgical cases) } & 24 & 7.3 & 18 & 8.6 \\
\hline \multicolumn{2}{|c|}{ Ovarall } & 327 & 61.0 & 209 & 38.9 \\
\hline
\end{tabular}

\section{Surgical cases}

\section{Abscess}

Abscess was recorded in $45.8 \%$ cattle and $5.6 \%$ goats (Table 1). Rahman et al. (2012) reported 1.1\% cattle and $1.3 \%$ goats affected with abscess at Patuakhali Science and Technology University Veterinary Clinic, Babugonj, Barisal. Hossain et al. (1986) who recorded 1.2\% cases of abscess in cattle and of Samad (2001) who reported $1.56 \%$ abscess cases in goats.

\section{Myiasis}

Myiasis was recorded in $20.8 \%$ cattle and $11.1 \%$ goats (Table 1). This observation supports the report of Rahman et al. (2012) who reported $24.7 \%$ cattle and $16.4 \%$ goats affected with myiasis. Prevalence of $11.0 \%$ (Rahman et al., 1972), 1.07\% (Nooruddin et al., 1986) and 2.20\% (Das and Hashim, 1996) of maggot-infested wounds has been reported in cattle from Bangladesh.

\section{Navel-ill}

Navel-ill was recorded only in $12.5 \%$ calf (Table 1). This observation supports the report of Rahman et al. (2012) who reported 10.1\% navel-ill in calves. Das and Hashim (1996) reported 6.40\% navel-ill in calves. However, Samad (2001) recorded $0.79 \%$ and $0.62 \%$ navel-ill cases in calves and kids, respectively. 


\section{R. Karim and others}

\section{Gid disease}

Gid disease was recorded only in one goat 5.6\% (Table 1). Samad (2001) and Rahman et al. (2012) recorded $5.38 \%$ and $2.5 \%$ gid disease in goats.

\section{Urolithiasis}

Urolithiasis was recorded in $20.8 \%$ cattle and $44.4 \%$ goats (Table 1). Samad (2001) and Rahman et al. (2012) reported very low percentage $(0.02 \%)$ and $(1.1 \%)$ of obstructive urolithiasis in cattle.

\section{Overgrown Hoof}

Overgrown hoofs were recorded only in $33.3 \%$ goats during this study period (Table 1). Samad (2001) reported $0.70 \%$ in goats and $0.02 \%$ cases of overgrown hoofs in cattle. Nooruddin et al. (1986) reported $1.12 \%$ prevalence of overgrown hoofs in cattle.

\section{CONCLUSION}

Occurrence of diseases was recorded during clinical examination of sick cattle and goats at Upazila Veterinary Hospital, Mohammadpur, Magura, Bangladesh. This study was conducted to detect the present situation of occurrence of clinical diseases and disorders in the study area. From the study, it was observed that both cattle and goats were most susceptible to parasitic infestation. Parasitic infestation causes heavy economic losses in every year. So, regular anthelmintics treatment should be given to control the parasitic diseases. The district has border area as a result diseases like FMD and PPR were frequently outbreaks in cattle and goat respectively. So restriction of movement and frontier vaccination program must be undertaken in border area. So, further research should be required to determine the accurate prevalence of disease and disorders in cattle and goat. Proper planning and program should be undertaken to prevent and control diseases and disorders of cattle and goat in the study area.

\section{REFERENCES}

1. Amin MR and Samad MA (1987). Clinico-therapeutic studies on gastrointestinal nematode infection in diarrhoeic cattle . Bangladesh Veterinarian 4: 25-28.

2. Das BC and Hashim MA (1996). Studies on surgical affections in calves. Bangladesh Veterinary Journal 30: $53-$ 57.

3. Haque ME, Samad MA and Rahman A (1988). Epizootiology investigation of Black quarter in cattle of Bangladesh. Bangladesh Veterinarian 5: 10-13.

4. Hoque MS and Samad MA (1996). Prevalence of clinical diseases in dairy cross-bred cows and calves in the urban areas in Dhaka. Bangladesh Veterinary Journal 30: 118-129.

5. Hoque MS and Samad MA (1997). Present status of clinical diseases of goats in the urban areas in Dhaka. Bangladesh Veterinary Journal 31: 35-40.

6. Hossain MA, Shaidullah M and Ali MA (1986). A report on surgical diseases and reproductive disorders recorded at the Veterinary Hospital of Bangladesh Agricultural University, Mymensingh. Bangladesh Veterinary Journal 20: $1-5$.

7. Hossain MI, Huq AKMM and Huque AKMF (1994). Pathological investigation on buffalo diseases in Bangladesh. III. Survey of buffalo diseases. Bangladesh Veterinarian 11: 123-127.

8. Howlader MMR, Chowdhury SMZH, Taimur MJFA and Johan S (1990). Fluke infestations of cattle in some selected villages of Bangladesh . Bangladesh Veterinarian 7: 45-47.

9. Kabir MH, Reza MA, Razi KMA, Parvez MM, Bag MAS and Mahfuz SU (2010). A report on clinical prevalence of diseases and disorders in cattle and goat at the Upazilla Veterinary Hospital, Ulipur, Kurigram. International Journal of Biological Research 2: 17-23.

10. Nooruddin M and Dey AS (1990). Further study on the prevalence of skin diseases in domestic ruminants of Bangladesh. Bangladesh Veterinarian 7: 75-81.

11. Nooruddin M and Rahman MS (1985). A note on bovine demodicosis in Bangladesh. Indian Journal of Veterinary Medicine 5: 139-140.

12. Nooruddin M, Sarker AJ, Baki MA, Ali MR, Dey AS and Hoque MF (1986). Prevalence of diseases of external organs of cattle. Bangladesh Veterinary Journal 20: 11-16.

13. Osmani ABMMG, Hossain MA, Rahman MM and Alam MR (2000). Corneal opacity in cattle: Prevalence and therapeutic evaluation of certain drugs. Bangladesh Veterinarian 17: 42-45. 
14. Pallab MS, Ullah SM, Uddin MM and Miazi OF (2012). A cross sectional study of several diseases in cattle at Chandanaish Upazilla of Chittagong district. Scientific Journal of Veterinary Advances 1: 28-32.

15. Pharo HJ (1987). Analysis of clinical case records from dairy co-operatives in Bangladesh. Tropical Animal Health and Production 19: 136-142.

16. Prasad J, Uoshi SV and Rekib A (1980). Studies on the clinico-pathics of grazing animals in tropics -corneal opacity syndrome. Indian Veterinary Journal 57: 310-315.

17. Rahman A, Ahmed JU and Haque MA (1975). Analysis of lameness of cattle admitted to the Veterinary hospital of Bangladesh Agricultural University. Bangladesh Veterinary Journal 9: 21-24.

18. Rahman A, Samad MA and Huq MM (1978). Clinico-pathological studies on psoroptic mange in a goat. Bangladesh Veterinary Journal 13: 53-55.

19. Rahman MA, Ali KM and Rahman A (1972). Incidence of diseases of cattle in Mymensingh. Bangladesh Veterinary Journal 6: 25-30.

20. Rahman MA, Islam MA, Rahman MA, Talukder AK, Parvin MS, and Islam MT (2012). Clinical diseases of ruminants recorded at the Patuakhali Science and Technology University Veterinary Clinic. Bangladesh Journal of Veterinary Medicine 10(1\&2): 63-73.

21. Rahman MM, Ali M and Hashem A (1999). Livestock disease problems in a selected area of Sherpur district. Bangladesh Journal of Training and Development 12: 205-210.

22. Rosenberger G (1979). Clinical Examination of Cattle. $2^{\text {nd }}$ edn., Verlag Poul Parey, Germany.

23. Samad MA (2000). Veterinary Practitioner's Guide. $1^{\text {st }}$ Pub. No. 07, BAU Campus, Mymensingh.

24. Samad MA (2001). Observations of clinical diseases in ruminants at the Bangladesh Agricultural University Veterinary Clinic. Bangladesh Veterinary Journal 35: 93-120.

25. Samad MA (2008). Animal Husbandry and Veterinary Science. $1^{\text {st }}$ pub., LEP pub No. 11. BAU Campus, Mymensingh.

26. Samad MA, Bari ASM and Bashar SA (1988). Gross and histopathological studies on bovine babesiosis in Bangladesh. Indian Journal of Animal Science 58: 926-928.

27. Samad MA, Islam MA and Hossain A (2002). Patterns of occurrence of calf diseases in the district of Mymensingh in Bangladesh. Bangladesh Veterinary Journal 36: 01-05.

28. Samad MA, Rahman A and Hossain MI (1979). Studies on Demodectic mange in cattle. Bangladesh Journal of Scientific Research 2: 7-13.

29. Sarker MAS, Hashim MA, Rahman MB and Begum H (1999). Studies on bovine lymphadenitis syndrome. Bangladesh Veterinarian 10: 6-8.

30. Sutradhar BC, Hossain MA and Alam MR (2000). Incidence of bloat and it response to certain drugs in cattle. Bangladesh Veterinarian 17: 37-41. 